\title{
Suitability of a Fixed Station Shrimp Abundance Survey in the Skagerrak-Norwegian Deeps for Stock Assessments and Associated Research
}

\author{
Stein Tveite \\ Institute of Marine Research, Flødevigen Marine Research Station \\ N-4817 His, Norway
}

\begin{abstract}
Since 1984, an annual fixed station survey for northern shrimp (Pandalus borealis) has been conducted during October-November within the Skagerrak and Norwegian Deeps. Abundance trends from this survey are similar to trends from Extended Survivor Analysis and landings per unit of effort statistics, consequently the survey should be useful for assessment and management purposes, including determination of year-class strengths. While 0 -group survey catch indices did give an early indication of year-class strength, I-group indices were more reliable for this purpose. Trends in shrimp abundance indices and other survey data including growth and time of sex reversal were positively correlated to environmental factors, including yearly averages of deep water temperatures, and the volume of Atlantic water flowing into the area. Consequently, the fixed station shrimp survey results should also be useful for investigations into the causes of changes in shrimp population dynamics in the Skagerrak-Norwegian Deeps area.
\end{abstract}

Keywords: abundance, Atlantic Ocean, northeast, recruitment, shrimp, temperature

\section{Introduction}

In the 1960 s the northern shrimp (Pandalus borealis) fishery within the Skagerrak-Norwegian Deeps area (Fig. 1) collapsed. Norwegian catches dropped from 9000 to 3000 tons from 1962 to 1966 , and fishers were forced to change target species or leave the fishing industry. Subsequently, landings increased slowly, the fleet was rebuilt and fishers' organizations became more concerned with management of the fishery. On their request the Institute of Marine Research, Norway, began a trawl survey in 1984, which has since been conducted annually during October-November.

Trawl surveys have commonly been used to estimate shrimp stock abundance (Stolyarenko and Ivanov, 1995; Harbitz et al., 1998; Cadrin et al., 1999), although it is recognized that stock biomasses are usually underestimated (Mohn et al., 1992). In the first years of investigations in the SkagerrakNorwegian Deeps area, the landed catch exceeded the estimated survey biomass. Consequently it was recognized that the survey could not provide absolute biomass estimates but only indices of abundance, which could be used to improve assessments based mainly on data from the commercial fishery. According to analytical assessment (ICES, MS 1999b) the commercial catch by the international fleet in the area consisted of $31 \%$ I-group and $42 \%$ II-group by weight on average. An early indication of year-class strength would therefore be very useful for management purposes. The purpose of this document is to determine if the I-group index obtained from the fixed station survey has, over the years, provided a reliable index of recruitment to the fishery. It also looks at how these indices correlate with environmental parameters and their potential use for investigations into the causes of changes in shrimp population dynamics in the Skarerrak-Norwegian Deeps area.

\section{Material and Methods}

The 1984 survey was originally planned as a stratified-random survey. However, topography limited the choices of trawlable locations on the Norwegian side of the Deeps, and experience from an 80 -year time series of beach seine hauls on the Norwegian Skagerrak coast (Tveite, 1971, 1992) stressed the importance of uniformity in gear, time and location of sampling in order to obtain reliable abundance indices. It was therefore decided to use a system of fixed stations (Fig. 1) as later recommended by Van der Meer (1997) for benthic species. Since 1984, sampling has been conducted by RV "Michael 


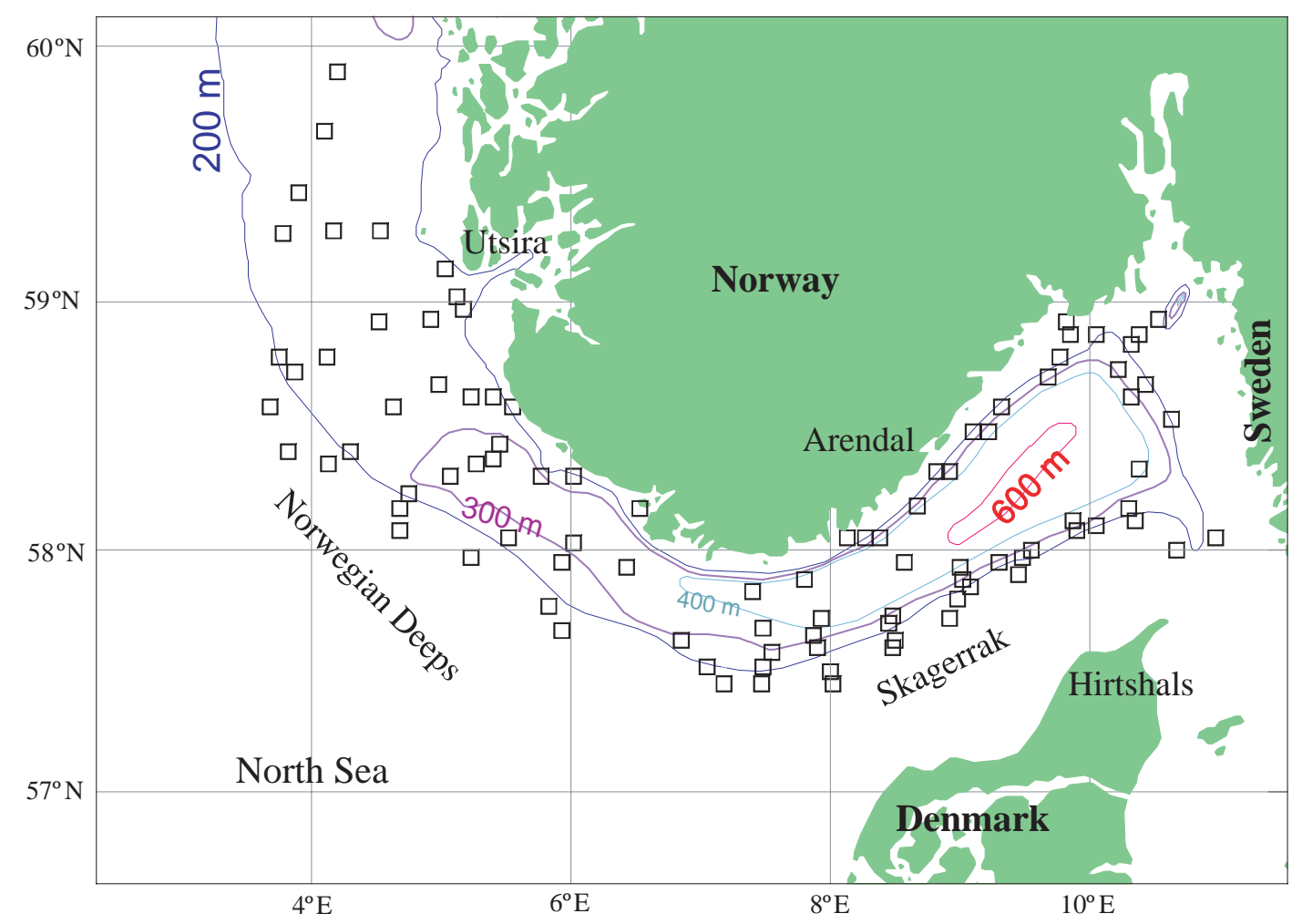

Fig. 1. Fixed station locations for shrimp surveys conducted by RV Michael Sars, on an annual basis during October-November since 1984.

Sars" using the Norwegian standard survey trawl: a Campelen 1800 sampling trawl (Engås and Godø, 1989) with $20 \mathrm{~mm}$ meshes in the belly, $6 \mathrm{~mm}$ codend liner, $40 \mathrm{~m}$ sweep lines, and rock hopper footrope gear. The trawl was towed at 3.0 knots prior to 1989 for $1.0 \mathrm{hr}$, thereafter standard towing time was $0.5 \mathrm{hr}$. The total catch from each set or an appropriate subsample of the total catch was sorted and total weight and numbers of $P$. borealis obtained. Oblique carapace lengths (nearest $\mathrm{mm}$ ) were obtained for approximately $200 P$. borealis per set. Sexual development stages were determined according to Rasmussen (1953). Within the Skagerrak Area there is no overlap in carapace lengths between 0-group and I-group males, therefore these groups were aged by eye. Males in the Norwegian Deeps and all females were separated into age groups by the Bhattacharya method as implemented in ELEFAN (Pauly, 1987).

Two indices are used in this paper: 1. Total numbers of shrimp (separated by sex and age) caught in all sets between 140-450 m depths, divided by the total distance trawled. The age structure was determined for the Skagerrak and Norwegian Deeps separately. 2. Stratified swept-area indices using 16 strata. Calculations of total numbers were based on an effective trawl opening of $11.7 \mathrm{~m}$ (Teigsmark and Øynes, MS 1983). Age structure was determined for each stratum separately.

Landings per unit of effort (LPUE) from the fishing fleets were derived from logbooks (Norwegian and Swedish in kg per hr; Danish in kg per day). The Danish and Swedish logbooks covered nearly 100\% of their landings, while the Norwegian logbooks covered only about $30 \%$. These data are used to tune the Extended Survivor Analysis (XSA) in annual assessments of the area by the International Council for the Exploration of the Sea (ICES, MS 1999a).

A hydrographical transect between Norway and Denmark across the deepest part of the Skagerrak has been sampled during monthly cruises since 1947 (Aure and Dahl, 1994). Before 1987 temperature was measured at standard depths by high precision thermometers, from 1987 onwards by the Neill Brown CTDsonde. The inflow of Atlantic water to the Norwegian Deeps has been calculated at a section westward from Utsira-Orkney (Skogen and Søiland, 1998). 


\section{Results and Discussion}

The relationship between the I- and II-group indices of the same year-class was quite poor (Fig. 2). Typical length distributions from both areas show no overlap between 0 -group and I-group shrimp. The Igroup is fairly well defined, but separation of older year-classes involved a considerable element of subjectivity (Fig. 3). In October, the 0 -group was still not fully available to the trawl, the extent of availability probably being dependent on yearly variations in environmental conditions. The I-group is therefore the most reliable age group for year-class abundance estimates.

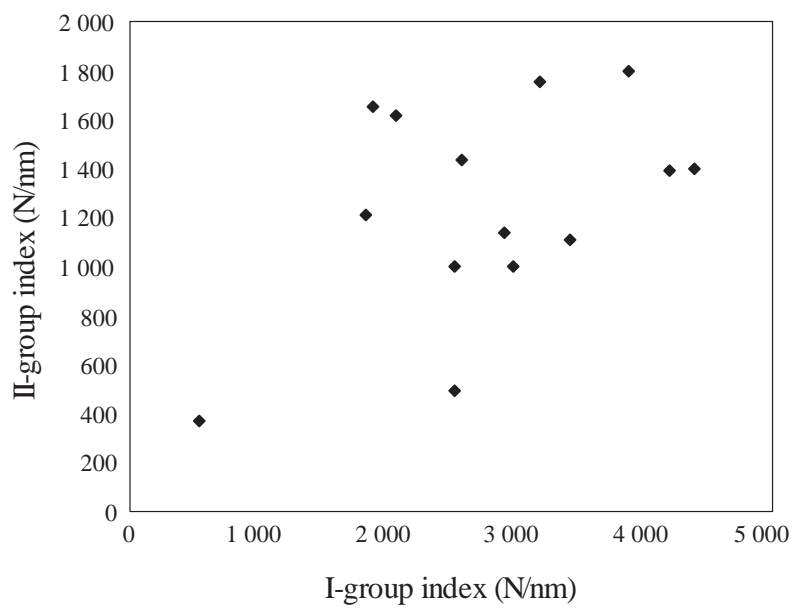

Fig. 2. Relationship $(R=0.47)$ between abundance indices in numbers per naut. mile $(\mathrm{N} / \mathrm{nm})$ of I-group shrimp of a year and II-group shrimp of the next year, for the 1983-96 year-classes.

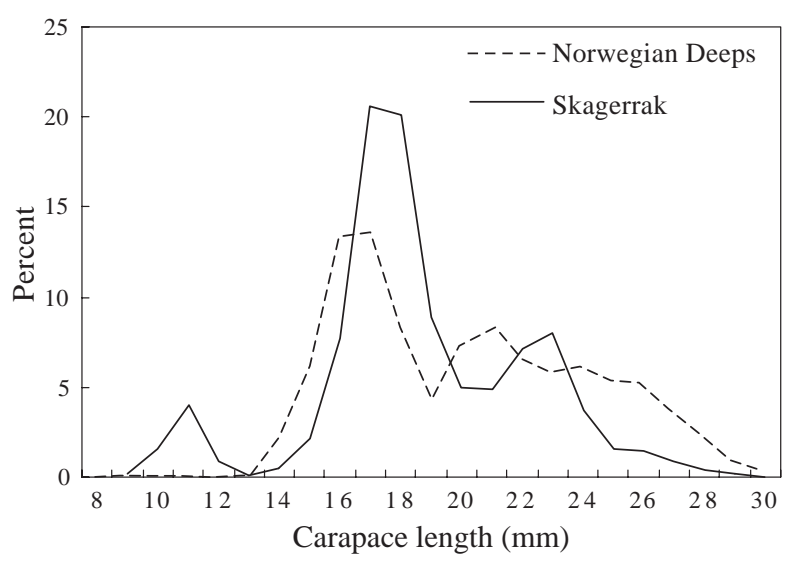

Fig. 3. Typical carapace length distribution of Pandalus borealis from the Skagerrak-Norwegian Deeps.
LPUEs by fleet used as abundance indices in assessments, survey abundance (total kg per mile) and total biomass calculated by XSA (ICES, MS 1999a) are presented as deviations from their average values in Fig. 4. The LPUE and survey indices were independent measures while the total biomass was partly dependent on these indices because they were used for tuning the XSA model. All indices followed the same increasing trend in the 1990s.

Table 1 shows the ratio of numbers per age group from the XSA to the swept area estimates. The I-IV groups, fully available to the trawl, are underestimated by the swept area method compared to the XSA analytical method by a factor averaging between 2 and 4 .

During 1984-98 the total catch of fish in the survey trawl followed the same trend as the total catch of shrimp (Fig. 5). However, there was no significant relationship between shrimp recruitment as measured by 1 -group survey indices, shrimp spawning stock $(R=$ $-0.09)$ from XSA, or total fish abundance $(R=-0.03)$ as measured by the survey trawl. For the time period and area considered, predation does not appear to have had any significant influence on recruitment and decreases in the spawning stock has not limited the production of new year-classes.

Available recruitment figures for fish stocks in the North Sea-North East Atlantic (ICES, MS 1999b) were all positively correlated to shrimp recruitment except whiting and autumn spawning herring (Table 2 ). This suggests that some common environmental factor(s) are influencing both shrimp and fish recruitment.

Both high and low temperatures are known to create dramatic reductions in Pandalid recruitment (Rasmussen, 1967; Dow, 1981). There was a positive correlation $(R=0.45)$ between the I-group index and the yearly average annual temperature measured below $250 \mathrm{~m}$ depth in the Skagerrak (Fig. 6). Since temperatures have varied well within the tolerance limits for $P$. borealis, it is likely that temperature itself is not the most important factor influencing year-class fluctuations. Changes in the flow of Atlantic deepwater into the Norwegian Deeps and Skagerrak influences a number of variables including temperature, currents and primary production which may be of importance to shrimp and fish recruitment (Iversen et al., MS 1998). Water flow during the second quarter of the year, when juvenile shrimp are pelagic, was 


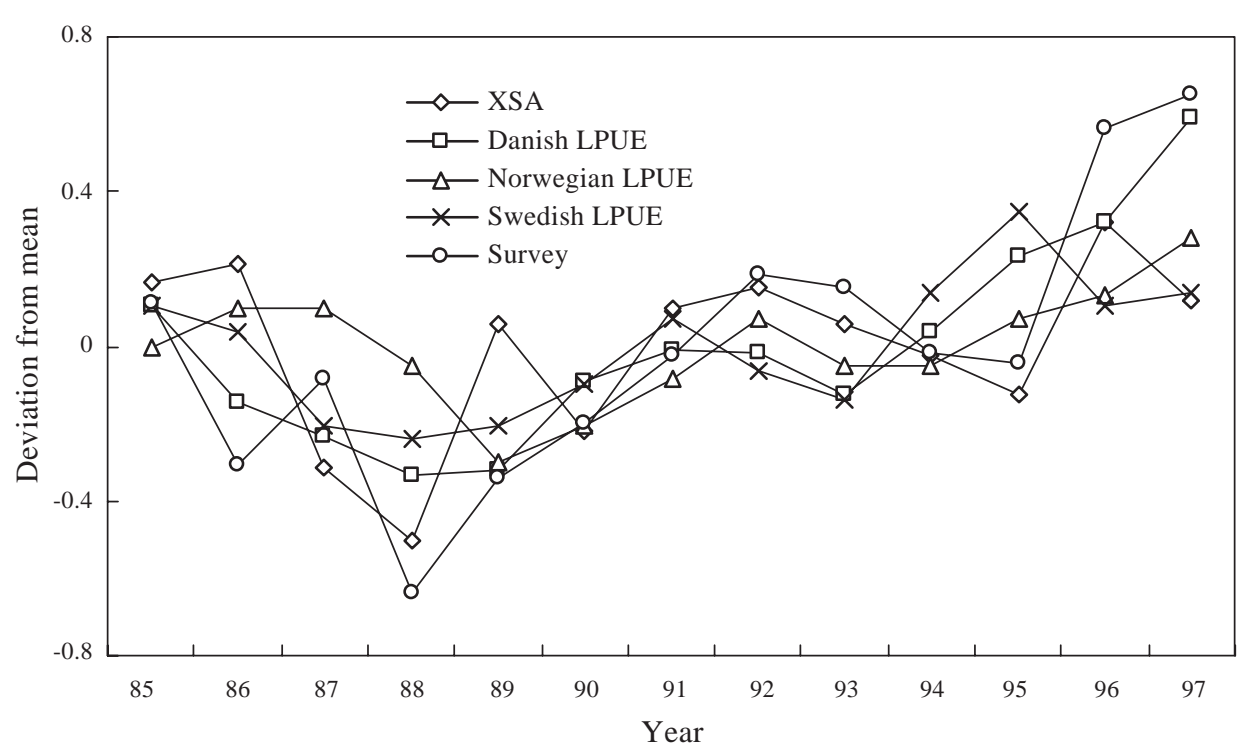

Fig. 4. Deviation from the mean for different indices of abundance of Pandalus borealis in Skagerrak-Norwegian Deeps.

TABLE 1. Extended Survivor Analysis (XSA) total numbersper-year-class divided by survey swept area estimates.

\begin{tabular}{lrrrrr}
\hline \hline Year & 0-group & I-group & II-group & III-group & IV-group \\
\hline 1985 & 60.22 & 2.80 & 3.41 & 1.41 & 1.06 \\
1986 & 105.32 & 7.32 & 5.70 & 6.14 & 4.28 \\
1987 & 94.76 & 2.49 & 2.56 & 1.56 & 5.22 \\
1988 & 85.89 & 12.08 & 5.30 & 1.73 & 5.06 \\
1989 & 22.41 & 4.56 & 2.63 & 2.43 & 5.01 \\
1990 & 39.00 & 5.67 & 3.02 & 2.96 & 10.70 \\
1991 & 53.27 & 3.32 & 3.42 & 3.23 & 2.04 \\
1992 & 13.01 & 2.96 & 2.81 & 2.12 & 2.57 \\
1993 & 33.98 & 4.52 & 2.16 & 1.75 & 2.02 \\
1994 & 55.03 & 4.10 & 5.15 & 0.86 & 0.70 \\
1995 & 120.12 & 5.02 & 4.14 & 1.66 & 1.93 \\
1996 & 31.07 & 3.42 & 2.36 & 1.52 & 3.35 \\
1997 & 53.18 & 3.85 & 2.20 & 0.92 & 0.23 \\
Average & 45.99 & 4.20 & 3.21 & 2.07 & 3.54 \\
St. dev. & 33.20 & 2.56 & 1.24 & 1.38 & 2.77 \\
\hline
\end{tabular}

positively correlated to I-group shrimp abundance the following year (Fig. 6, $R=0.55$ ). Unfortunately, there are no suitable series on variations in primary or secondary production.

Environmental factors are also known to influence growth and sex reversal of Pandalids (Appollonio et al., 1986; Skuladottir and Petursson, 1999). In the Skagerrak up to $37 \%$ of the I-group and all of the IIgroup shrimps are females in October. In the

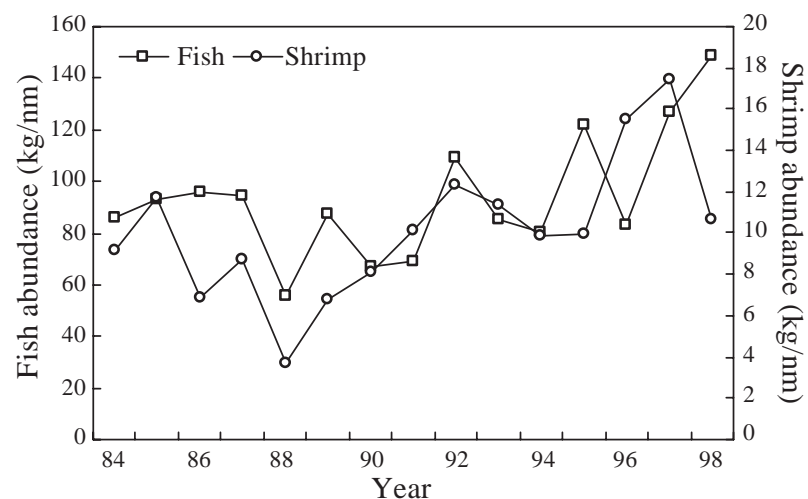

Fig. 5. Comparison of abundance (catch-per-nautical mile) of all fish species and Pandalus borealis in the Skagerrak-Norwegian Deeps, 1984-98.

Norwegian Deeps there is a great variation in the time of sex reversal, with 28 to $93 \%$ of the shrimp becoming females at age 2 (Fig. 7). This was positively correlated to the yearly average temperature $(R=0.6)$ for the 1984-97 period, however, if 1998 figures are included, the correlation drops to $R=0.32$. With the relatively high temperatures and faster growth rates in 1998, one would expect the II-group to be relatively large with a high female proportion. However the proportion of female II-group and the average size of II-group males were among the lowest observed. It is possible that the record high abundance of mature females from the 1995 and 1996 year-classes in 1997 and 1998 decreased the percentage of early sex reversals i.e. increased the average size at sex reversal, as suggested 
TABLE 2. Correlation coefficients $(R)$ between year-classes of Pandalus borealis as survey I-group indices and recruitment of different fish species in the North Sea and North East Atlantic estimated by ICES, 1985-97. (ICES, MS 1999b).

\begin{tabular}{llc}
\hline \hline \multicolumn{1}{c}{ Species } & \multicolumn{1}{c}{ Area } & $R$ \\
\hline Blue whiting Micromesistius poutassou & NE Atlantic Ocean & 0.57 \\
Mackerel Scomber scomber & NE Atlantic Ocean & 0.36 \\
Hake Merluccius merluccius & NE Atlantic Ocean & 0.27 \\
Sandeel Ammodytes spp. & North Sea & 0.39 \\
Saithe Pollachius virens & North Sea & 0.39 \\
Norway pout Trisopterus esmarki & North Sea & 0.19 \\
Cod Gadus morhua & North Sea & 0.15 \\
Haddock Melanogrammus aeglefinus & North Sea & 0.14 \\
Herring Autumn sp. Clupea harengus & North Sea & -0.13 \\
Whiting Merlangius merlangus & North Sea & -0.15 \\
\hline
\end{tabular}

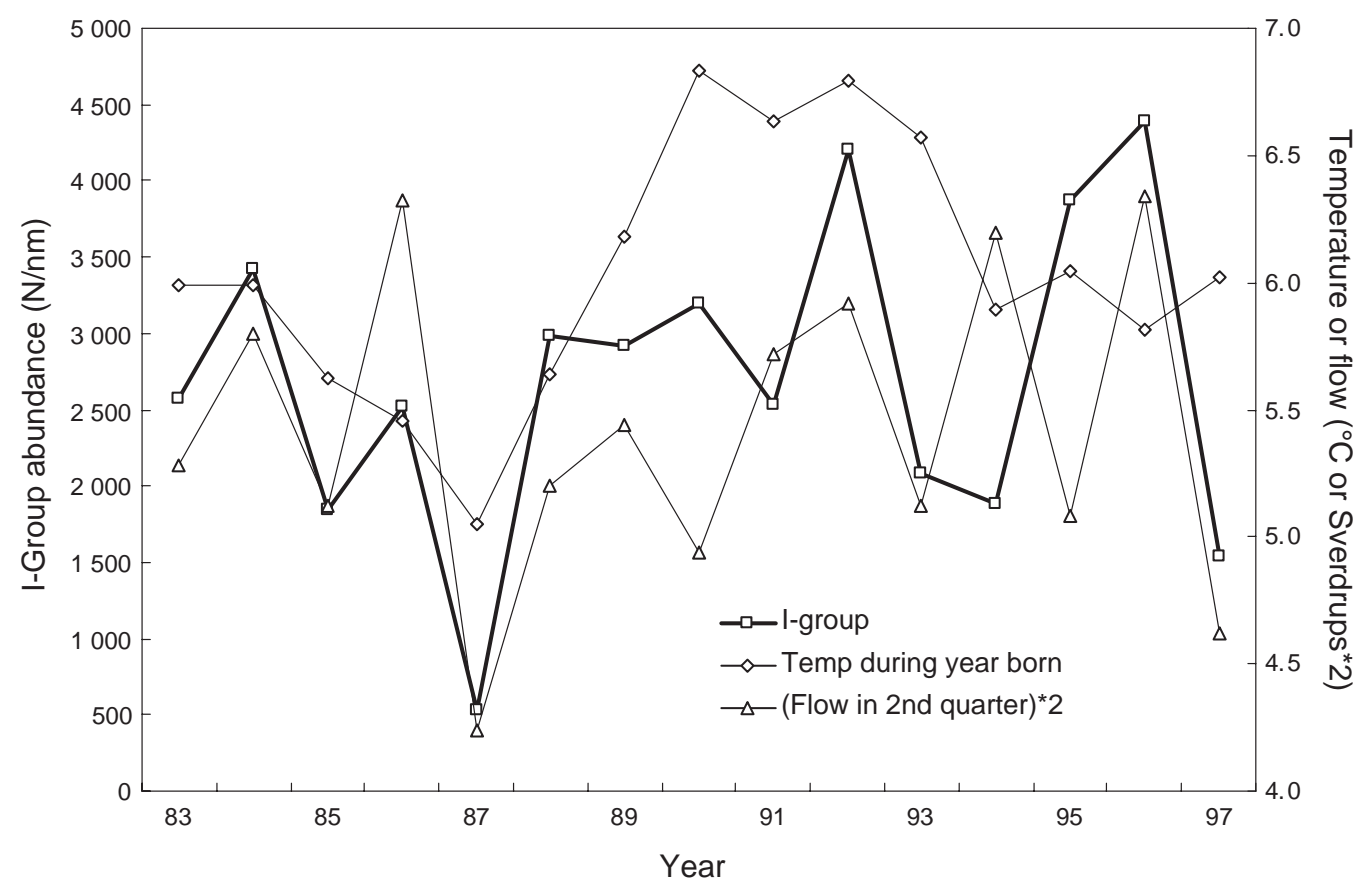

Fig. 6. Abundance index of I-group shrimp (numbers per naut. mile) in relation to yearly average temperature at $>250 \mathrm{~m}$ depths in the Skagerrak and the flow of Atlantic deepwater (1 Sverdrup $=1$ million $\mathrm{m}^{3}$ per second) into the Skagerrak-Norwegian Deeps area during the 2 nd quarter of the year.

by Charnov and Bergström (1987) and Charnov and Anderson (1989). On the other hand the decrease in size of the male II-group, in spite of the high temperature, could indicate a density dependant growth effect as described by Koeller et al. (2001).

In conclusion, comparisons with commercial catch indices and analytical assessment results indicate that the Norwegian fixed station survey provides acceptable indicators of year-class strength for I-group Pandalus borealis. In addition, environmental factors such as temperature and volume of Atlantic deep water flowing into the SkagerrakNorwegian Deeps area correlate with recruitment, growth and timing of sex reversal as determined by the fixed station survey, indicating that survey results are also useful for investigations into the causes of changes in shrimp population dynamics in the area. 

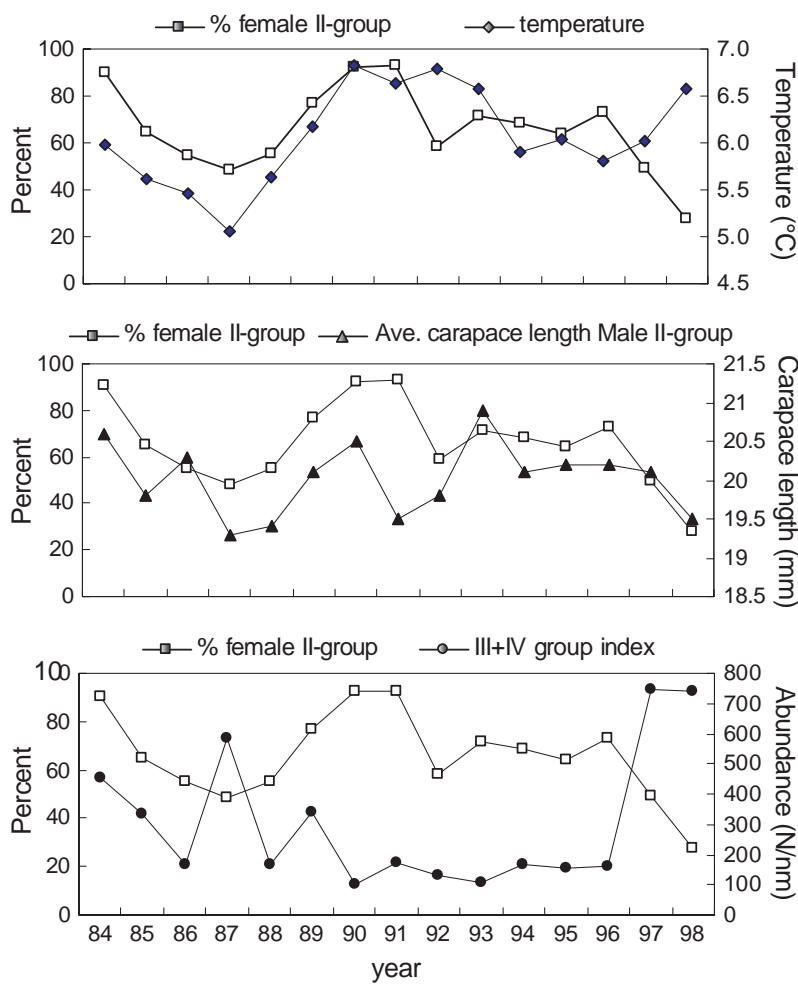

Fig. 7. Percentage of the II-group shrimp in the Norwegian Deeps that are female, compared to average yearly temperature, carapace length of male II-group shrimp and abundance of mature III+IV group females.

\section{References}

APPOllonio, S., D. K. STEVEnSON, and E. E. DUNTON, Jr. 1986. Effects of temperature on the biology of the northern shrimp Pandalus borealis, in the Gulf of Maine. NOAA Tech. Rep, NMFS, 42: $22 \mathrm{p}$.

AURE, J., and E. DAHL. 1994. Oxygen, nutrients, carbon and water exchange in the Skagerrak Basin. Con. Shelf Res., 14(9): 965-977.

CADRIN, S. X., S. H. CLARK, D. F. SCHICK, M. P. ARMSTRONG, D. MCCARRON, and B. SMITH. 1999. Application of Catch-Survey Models to the Northern Shrimp Fishery in the Gulf of Maine. North Am. J. Fish. Man., 19(2): 551-568.

CHARNOV, E. L., and B. BERGSTRÖM. 1987. Alternative life histories in sex changing shrimp: A phenotype limited ESS. Evolutionary Ecology, 1(2): 107-111.

CHARNOV, E. L., and P. J. ANDERSON. 1989. Sex change and population fluctuations in pandalid shrimp. Am. Nat., 134(5): 824-827.

DOW, R. L. 1981. Temperature cycles and northern stocks Fishing News International, 20(3): 21.

ENGÅS, A., and O. R. GODØ. 1989. Escape of fish under the fishing line of a Norwegian sampling trawl and its influence on survey results. $J$. $d u$ Cons., 45: 269-276.

HARBITZ, A., M. ASCHAN, and K. SUNNANÅ. 1998. Optimal effort allocation in stratified, large area trawl surveys, with application to shrimp surveys in the Barents Sea. Fish. Res., 37: 107-113.

ICES. MS 1999a. Report of the Pandalus Assessment Working Group. ICES C.M. Doc., No. 1999/ACFM:5, Ref. G. 33 p.

MS 1999b. Extract of the report of the Advisory Committee on Fishery Management October, 403 p.

IVERSEN, S. A., M. D. SKOGEN, and E. SVENDSEN. MS 1998. Influx of Atlantic water and feeding migration of Horse Mackerel. ICES C. M. Doc., No. R: 18.

KOELLER, P., R. MOHN, and M. ETTER. 2001. Density dependant sex change in northern shrimp Pandalus borealis on the Scotian Shelf. J. Northwest Atl. Fish. Sci., 27: 107-118 (this volume).

MOHN, R. K., D. G. PARSONS, AND L. SAVARD. 1992. Report of Canadian Fisheries Scientific Advisory Committee Special Meeting, Invertebrates and Marine Plants Subcommittee, Shrimp Management Alternatives, December 5-8, 1989. Ottawa, Canada. Can. Tech. Rep. Fish. Aquat. Sci., 1884: iv +30 p.

PAULY, D. 1987. A review of the ELEFAN system for analysis of length-frequency data in fish and aquatic invertebrates. ICLARM Conf. Proc., 13: 7-34.

RASMUSSEN, B. 1953. On the geographical variation in growth and sexual development of deep sea prawn (Pandalus borealis kr.). Fiskeri-dir. Skr. Havunders, 10 (3): $160 \mathrm{p}$.

1967. Temperaturforhold og rekefisket i Skagerrak 1962-1966. Fisken og Havet, 3: 17-22.

SKOGEN, M. D., and H. SØILAND. 1998. A User's guide to NORWECOM v2.0. The Norwegian Ecological Model system Fisken og Havet, 18: 42 p.

SKÚLADÓTTIR, U., and G. PETURSSON. 1999. Defining populations of northern shrimp, Pandalus borealis (Krøyer 1838), in Icelandic waters using the maximum length and maturity ogive of females. Rit Fiskideildar, 16: 247-262.

STOLYARENKO, D. A., and B. G. IVANOV. 1995. An experimental study of the variability of shrimp (Pandalus borealis) catches. ICES Mar. Sci. Symp., 199: 364-369.

TEIGSMARK, G., and P. ØYNES. MS 1983. Norwegian investigations on the deep sea shrimp (Pandalus borealis) in the Barents Sea in April-May 1983 and in the Spitsbergen area in July 1983. ICES C. M. Doc., No. $\mathrm{K}: 46 \mathrm{p}$.

TVEITE, S. 1971. Fluctuations in year-class strength of cod and pollock in southeastern Norwegian costal waters during 1920-1969. Fiskeridir. Skr. Havunders., 16: $65-76$.

1992. Prediction of year-class strength of coastal cod (Gadus morhua) from beach seine catches of 0-group. Flødevigen rapportserie, 1: 17-23.

VAN DER MEER, J. 1997. Sampling design of monitoring programmes for marine benthos: a comparison between the use of fixed versus randomly selected stations. J. Sea Res., 37: 167-179. 